\title{
PROBLEMAS DA EDUCAÇÃO: O CASO DA PSICOPEDAGOGIA
}

OdAIR SASS

\begin{abstract}
RE SU M 0 : Neste artigo é discutida a relevância dos problemas psicopedagógicos recorrentes das determinações internas e externas à educação escolar, a par do equívoco da pretensão de regulamentar a psicopedagogia como mais uma profissão da esfera educacional. D estaca a questão da regulamentação das profissões de nível superior no Brasil e as raízes variadas da psicopedagogia desde o período imediato após a Segunda Guerra Mundial.

Palavras-chave: Psicologia. Psicopedagogia. Educação. Profissões regulamentadas.
\end{abstract}

\section{Problemsin education: THE CASE OF PSYCHO-PEDAGOGY}

A BSTRA CT: Discussed in this article is the relevance of recurring psycho-pedagogical problems originated inside and outside formal education, as well as the dubious intention to regularize psychopedagogy as yet another profession within the educational sphere. Emphasized here is the question of regularizing the university professions in Brazil and the varied roots of psycho-pedagogy from the period immediately following the Second World War onward.

Key words: Psychology. Psycho-pedagogy. Education. Regularized professions.

* Psicólogo, doutor em Psicologia Social, professor da Pontifícia Universidade Católica de São Paulo (PUC-SP) e pesquisador da Universidade de Taubaté (UnITAU). E-mail: ehps@pucsp.br 
A idéia de que as soluções psicopedagógicas de muitos problemas da educação escolar são novas, digamos, tal como têm sido difundidas a partir dos anos de 1980, esboroa-se à medida que analisamos esses problemas à luz das relações da psicologia com a pedagogia, no Brasil.

Para evidenciar a procedência dessa conclusão, são aqui consideradas (I) as distinções entre ciência e profissão tais quais ainda são praticadas no país, (II) a educação como campo de conhecimento científico e as disciplinas conexas a ele, especialmente a psicologia, para daí (III) indicar que questões psicopedagógicas, próprias da esfera educacional, devem ser distinguidas da reivindicação de regulamentar a psicopedagogia como profissão.

Espera-se, ao final, contribuir para a identificação de fatores que se mantêm estritamente relacionados e ensejam a proposição de soluções aparentemente novas para os velhos problemas reais da educação escolar brasileira: a qualidade da formação de profissionais do nível superior preparados para atuarem na educação e a óptica corporativa com que os problemas da educação são tratados pelos diversos profissionais.

Sem a pretensão de apresentar um sumário histórico, ainda que breve, das profissões regulamentadas no Brasil, em particular daquelas que exigem, como critério de formação e exercício, o ensino superior - em geral, por aqui denominadas de profissões liberais -, vale ressaltar duas tendências contraditórias: uma de regulamentação das atividades profissionais de níveis médio e superior, forte ao longo do século XX, e outra de desregulamentação de boa parcela daquelas atividades, bastante enfatizada no Brasil, em meados de 1990, por ocasião dos debates no Congresso Nacional acerca da aprovação da Lei de Diretrizes e Bases da Educação Nacional (LDB/ 96).

No Brasil, as profissões de nível superior regulamentadas mais antigas são, como se sabe: 0 direito, a medicina e as engenharias, praticadas e formalizadas desde o século XIX. Contudo, é no decorrer principalmente dos primeiros dois terços do século passado que ocorre um processo intenso de regulamentação das profissões de níveis médio e superior. Assim, por exemplo, a psicologia, introduzida por aqui, desde o final do século X IX e ex- 
pandida no decorrer do XX, nos campos médicos e educacionais, foi regulamentada como profissão somente em 1962. ${ }^{1}$

A esse processo de regulamentação das profissões se contrapõe, acentuadamente a partir dos anos de 1990, proposições, cultivadas à direita e à esquerda, com 0 intuito de desregulamentar a maioria das profissões de nível superior brasileiras.

D esnecessário é relembrar que diversas profissões de nível médio, bastante requisitadas durante a industrialização no país, hoje sequer são lembradas ou se transformaram em raridades; por exemplo, relojoeiro, torneiro-mecânico, tipógrafo, entre outras.

Uma conhecida investida contra as profissões regulamentadas foi aquela desferida por um senador da República, quando transitava no Senado a proposta da Lei de Diretrizes e Bases da Educação Nacional apresentada pelo senador D arcy Ribeiro. Pois bem, aquele senador propôs a inclusão de um artigo que fixava, mais ou menos, o seguinte: "São consideradas regulamentadas no território nacional aquelas profissões da saúde, direito e engenharias".

Afora 0 aparente despropósito de se pretender regular o mercado de trabalho por meio de uma lei educacional - em nome do combate ao corporativismo dos profissionais e à reserva de mercado decorrente da profissionalização vigente no país - , a intenção do legislador era, de fato, atender às exigências do capital.

Não se trata aqui de argumentar em favor dos corporativismos perniciosos; trata-se de admitir que a tese da desregulamentação para um abstrato "mercado de trabalho" é como querer matar o doente pelo remédio que lhe é ministrado.

Acresça-se um elemento estrutural da legislação brasileira que regula a relação entre o ensino superior e 0 exercício das "profissões liberais". Trata-se, em linhas gerais, da seguinte regra jurídico-política: para a regulamentação de uma profissão é necessária a formação profissional em um curso de nível superior correspondente. Contudo a recíproca não é verdadeira, isto é, pode haver um curso superior sem que haja uma profissão regulamentada correspondente. Mais ainda, pode haver cursos e respectivas profissões, sem que haja conselhos profissionais - instância orientadora e fiscalizadora de profissões regulamentadas, administradas pelo corpus profissional por concessão do Estado, componente decisivo para se discutir e 
compreender o corporativismo. Para não multiplicar os exemplos, mencione-se apenas os casos da pedagogia (curso superior sem profissão correspondente ${ }^{2}$ ), do jornalismo e da sociologia (cursos superiores com profissões correspondentes regulamentadas, organizadas por associações profissionais de natureza sindical em vez dos conselhos concedidos pelo Estado).

Cabe por fim assinalar ainda mais um nó desse intricado emaranhado das profissões de nível superior no país: trata-se dos complexos vínculos estabelecidos entre ciência e profissão. Mais uma vez, não se pretende aqui propor soluções, visa-se antes a apontar para o problema.

Como é sobejamente conhecido, de há muito tempo, os conselhos profissionais insistem, às vezes de modo apropriado e pertinente e, no mais das vezes, de modo açodado, movidos mais pela apetência que pela competência, em querer legislar não apenas sobre a atuação e o exercício profissionais, mas, acima de tudo, sobre os conhecimentos científicos desenvolvidos especialmente em centros de pesquisa e universidades.

Disso decorre mencionar a distinção, por vezes ocultada, entre o conhecimento científico elaborado de acordo com o que se convencionou denominar de ciência social - isto é, campos de conhecimento relativos a objetos, conteúdos e métodos específicos - e as práticas profissionais - isto é, atividades circunscritas, orientadas por referências teóricas, técnicas e procedimentos aplicados a problemas sociais e à prestação de serviços.

Se, indiscutivelmente, ciência e profissão mantêm nexos entre si, como esferas que se referem uma à outra, não é menos verdadeiro 0 fato de que tais nexos nem são diretos, nem simétricos. Assim, uma coisa é o conselho profissional orientar e fiscalizar a atuação de seus filiados no que tange ao campo científico que lhe dá fundamento, e recorrer aos centros de pesquisa, seja para dirimir questões profissionais, seja para auxiliar o aprimoramento da profissão, outra coisa, muito diferente, é pretender legislar sobre a ciência e, por decorrência, sobre as instituições que a produzem. Não menos danosa é a recíproca, ou seja, as universidades, os centros de pesquisa, as associações profissionais (distinguíveis dos conselhos) pretenderem impor suas regras, como salvaguardas e protetoras do "bom" exercício profissional, sem as devidas mediações. 
D e toda maneira, é preciso registrar que a relação entre ciência e profissão guarda vínculos importantes com aquela estabelecida entre 0 Estado e a regulamentação das profissões no país, ou seja, com o chamado corporativismo. Questõ̃es que a mim me parecem de decisiva relevância nos debates acerca das funções do Estado e das instituições sociais, na fase atual de internacionalização plena do capital e de expansão violenta da sociedade administrada.

\section{II}

A propugnação da pedagogia como ciência da educação remonta, na modernidade, ao século XVIII e, marcadamente, ao início do XIX, com Johan W. Herbart. Herbart, ciente do papel decisivo que a educação e a instituição escolar passariam a desempenhar para a formação do sujeito, destacava a ética e a psicologia - esta ainda enfaticamente filosófica - como as ciências-pilares de uma pedagogia geral; a primeira voltada para os fins e a segunda voltada para os meios da educação.

A criação das ciências empíricas - em especial as biológicas e sociais - , no decorrer do século XIX e nas primeiras décadas do XX, permite asseverar que não só a pedagogia não se constituiu como ciência unitária - posto que falta a ela a formulação básica de objetos de estudo - bem como se tornou suscetível a toda sorte de influências conjunturais, emanadas das ciências que, a cada momento, estão em evidência. Assim, ora a educação é alvo da sociologia, da antropologia, da história, da economia, ora da biologia e da psicologia. Nestes termos, parece-nos que a pedagogia e a esfera da educação se converteram mais propriamente em campo de conhecimento e de intervenção variada que em ciência e práticas profissionais especializadas. Mais se diz sobre e se constatam as crises da educação, de modo extrínseco, e menos se ocupa de seus problemas imanentes e se realizam as críticas radicais necessárias que o campo suscita.

D essas oscilações e da influência variada é de todo modo destacável aquela exercida pela psicologia na esfera educacional. Resultante da emergência tardia do indivíduo como categoria social, destacadamente defendida pelo Iluminismo no plano filosófico-científico, pela Revolução Francesa no plano político-institucional e pelas relações burguesas de produção, a psicologia vai se constituindo nas lutas da metafísica com a ciência, do capital com 
o trabalho, das instituições voltadas à formação do sujeito com 0 controle social do indivíduo.

D eterminada pelas relações sociais burguesas, que, antes de presumir o sujeito racional tal como fizera Kant, passou a constituílo, carente de objeto, como tão bem constatou Hegel, a psicologia realizava-se em meios tão distintos quanto aqueles da indústria, da escola, dos hospitais e dos locais adequados para atendimento privado da privacidade do indivíduo, com o intuito, é claro, de adaptá-lo antes que de contribuir para sua emancipação efetiva.

Por sua vez, a determinação da psicologia sobre o campo educativo ensejou o que muitos denominam corretamente de psicologismo, isto é, a redução da explicação de fenômenos sociais e políticos complexos e objetivos à esfera da subjetividade, das vontades, dos interesses e das limitações individuais.

Entre os fatores objetivos e subjetivos da educação a psicologia privilegia os últimos; perspectiva que, de um lado, está de acordo com o seu objeto, ou seja, o indivíduo, e, de outro, põe-se em desacordo com ele, na medida em que atribui exclusivamente ao indivíduo seus impedimentos, fracassos, desempenhos e realizações. D aí, sob a óptica da teoria crítica, a psicologia padecer da contradição, insolúvel na sociedade burguesa, de defesa do indivíduo e também de responsabilizá-lo solenemente por suas ações.

Ao abstrair as condições objetivas que determinam a conduta humana, a psicologia converte-se em ideologia. Em parte, a subordinação ou a abstração da objetividade explica a insistência de diversas teorias psicológicas propugnarem o isolamento do indivíduo das circunstâncias em que efetivamente se comporta, fomentando assim um recorrente modo de agir sobre o indivíduo, aqui provocativamente denominado de clinicalismo. ${ }^{3}$

Tal modo de agir é um dos traços mais marcantes da intervenção da psicologia no campo educacional e em sua relação com a pedagogia. A contraface disso pode ser assim sintetizada: se o psicólogo é um "quase-médico", como vaticinou um psicólogo norte-americano, no final da década de 1960, então muitos pedagogos são, guardadas as proporções, "quase-psicólogos". Em outras palavras, uma das oscilações da pedagogia para 0 enfrentamento dos problemas pedagógicos, nos termos aqui apresentados, corresponde à modalidade clinicalista do psicologismo. 
Um desdobramento dos nexos estabelecidos entre as ciências e a regulamentação das profissões e especificamente entre a psicologia e a pedagogia, no Brasil, é aquele relativo às especializações e à prestação de serviços destinados à resolução de problemas escolares ou psicopedagógicos, conhecidos estes também como serviços periescolares.

Pretende-se aqui indicar, a título introdutório, portanto, mais como hipóteses orientadoras para explorações posteriores e menos como conclusões peremptórias, que a psicopedagogia tal qual emerge no Brasil, enfaticamente a partir dos anos de 1980, isto é, como "solução nova", com o objetivo de prestar serviços especializados para resolver as mazelas do fracasso escolar e os problemas de aprendizagem dos alunos, é uma reposição parcial, fortemente psicologista (na acepção mencionada anteriormente) e "clinicalista", de um conjunto de proposições teóricas e modos institucionais de tratamento dos problemas escolares, desenvolvidos, em particular, por educadores e psicólogos franceses que remontam ao período imediatamente posterior à Segunda Guerra, por meio da criação de centros psicopedagógicos, quando "o Ministério da Educação nacional e o Ministério da Saúde tomaram consciência da necessidade de ação organizadora em favor de indivíduos cujos problemas não dependiam nem da falta de meios, nem de simples má vontade" (Beaufils, 1974, p. 328).

Em termos mais precisos, a psicopedagogia, ${ }^{4}$ tal como foi desenvolvida em França, incide sobre aspectos distintos da organização escolar, a saber: 1) como modo prático de o professor conduzir, propor, orientar as atividades dos alunos, a psicopedagogia é compreendida como didática, conforme a referência seja a classe tradicional (escola tradicional), a classe nova (educação nova) ou uma classe ativa (escola ativa) e suas variantes (cf. Lefèvre, 1974, p. 88-128); 2) como modo de distribuir em seqüências, bem como identificar os aspectos psicológicos envolvidos no ensino e na aprendizagem de conteúdos das disciplinas escolares, a psicopedagogia é inscrita nas questões referentes à psicologia e ao currículo (cf. Leboutet, 1974, p. 243-256); 3) como modo institucional de tratar as crianças com problemas de conduta e de aprendizagem por meio da criação de centros psicopedagógicos (cf. Beaufils, 1974, p. 325-334; 4) sob a denominação de pedagogia curativa escolar, com inclinações indiscutivelmente tera- 
pêuticas, como modo de tratar "(...) crianças e adolescentes inaptas, que, embora inteligentes, têm maus resultados escolares e para quem os exames feitos levaram a pensar que uma psicoterapia seria inútil ou insuficiente (...) tratamento baseado em exercícios escolares (...)" (D ebesse apud Bley, 1974, p. 338).

À luz da argumentação aqui apresentada, é razoável concluir que a psicopedagogia no Brasil pretende privilegiar os problemas de conduta e de aprendizagem bem como a perspectiva da psicologia clínica de tratá-los; em suma, a psicopedagogia, no Brasil, pretende ser inserida, de modo predominante, como "solução nova" dos velhos problemas escolares os quais tanto a pedagogia quanto a psicologia (e suas variantes psicologia da educação, psicologia escolar e psicologia clínica) fracassaram, por fatores objetivos, solenemente em resolver.

Apresse-se aqui em esclarecer dois pontos importantes: $1^{\circ}$ ) todo o esforço empreendido pelos educadores franceses para distinguir a psicopedagogia da psicologia clínica e das psicoterapias não logrou a êxito - caso contrário não estaríamos assistindo ao retorno de mais um psicologismo sem freios no campo educativo; $2^{\circ}$ ) tanto quanto é preciso admitir que muitos dos problemas psicopedagógicos permanecem ou se agravam na educação escolar brasileira, deve-se registrar, com vigor, que a solução de tais problemas não está na dependência direta de mais especializações e profissionalizações - a questão é, primeiro, política e institucional e, subordinadamente, técnica e profissional -; menos ainda a resolução de tais problemas está na dependência de algo como "pedagogia curativa escolar".

Quanto ao primeiro ponto, Jean Vial, um dos autores do tratado referido anteriormente, inclui, entre os fatores externos de mudança da pedagogia contemporânea, o pedocentrismo, isto é, o deslocamento das preocupações pedagógicas dos meios e das técnicas para 0 sujeito da ação pedagógica, subdividido, por sua vez, em uma biopedagogia e numa psicopedagogia (Vial, 1974, p. 453-485). Esta, apesar de se nutrir das pesquisas empíricas e experimentais levadas a cabo pela psicologia escolar bem como dos resultados da psicologia do desenvolvimento, de sorte a realizar a antiga perspectiva de uma escola "bem centrada na criança", não se deveria reduzir à psicologia escolar ou mesmo a uma psicologia ligada à biologia do conhecimento. Para 0 autor, uma psicopedagogia eficaz inclui nas práticas escolares e na formação do professor, além dos conhecimentos menciona- 
dos, o fator social que determina em larga medida as atividades pedagógicas de ensino e aprendizagem (idem, ibid., p. 481-484).

A psicopedagogia, admitida como esforço de articulações de conhecimentos produzidos por ciências tão distintas quanto a biologia, a psicologia, a medicina, a linguística, a sociologia, é de todo modo, de acordo com os autores que a reivindicaram, uma realização da educação escolar, no âmbito da escola e da sala de aula; não uma realização em clínicas e consultórios, ou por um modo clinicalista de analisar os problemas pedagógicos.

Com relação ao segundo ponto é desejável, por tudo o que até aqui se disse, que uma coisa é reconhecer a permanência e o agravamento dos velhos problemas de ensino e aprendizagem bem como a emergência de novos problemas, que bem podemos nomear de problemas psicopedagógicos, outra coisa, bastante distinta, é a pretensão de que a resolução daqueles problemas dependa da regulamentação de uma nova profissão para dar legalidade a um novo profissional da educação, recorrendo ao velho procedimento de isolar o problema (leia-se 0 aluno) das condições concretas em que se manifesta (leia-se escola, relações sociais entre professor e aluno, dificuldades e impedimentos decorrentes de métodos e conteúdos do ensino).

\section{À guisa de conclusão}

Este artigo foi redigido com a finalidade precípua de suscitar algumas questões acerca dos problemas psicopedagógicos. Assim, terá cumprido sua função se contribuir para o entendimento de que as graves dificuldades da educação brasileira não serão superadas de modo pontual ou por meio de soluções aparentemente novas, marcadas pelos conhecidos procedimentos técnicos da psicologia.

É certo que não estão aqui em julgamento as sinceras intenções dos profissionais da educação ou daqueles que, atuando em áreas profissionais conexas, estão comprometidos com a educação.

Se, de fato, a especificidade dos problemas pedagógicos exige, para que estes sejam resolvidos, esforços conjugados de investigações e intervenções das distintas disciplinas auxiliares da educação bem como da competência profissional, não nos parece razoável deixar de indicar que, em tempos bicudos como este, a crítica ao fracasso das intervenções profissionais na educação, no- 
meadamente da psicologia e da pedagogia, resulte, em nome do combate ao corporativismo, em mais corporativismo.

Aliás, parece plausível que um esforço para sustentar a superação dos abismos existentes entre a psicologia e a pedagogia na educação, com base na articulação dos conselhos profissionais e das entidades sindicais da psicologia, das associações de professores, dos centros de educação, de pesquisadores de universidades e das instâncias legislativas comprometidas com a escola pública, visasse com seriedade e crítica às possibilidades de resolução dos problemas psicopedagógicos que, não menos que outros estruturais, causam 0 sofrimento psíquico de tantas crianças, jovens, professores e pais, bem como o fracasso escolar.

Recebido em julho de 2003 e aprovado em outubro de 2003.

\section{Notas}

1. Lei n 4.119, de 27/ 8/ 1962 (cf. Manual do CRP, 6ª Região, 1995).

2. O fato, por exemplo, de a legislação educacional brasileira garantir, desde a década de 1960, que 0 ensino da disciplina Psicologia da Educação para o Ensino Médio deve prioritariamente ser atribuído ao pedagogo antes que ao psicólogo (fato gerador de reiterados conflitos nas esferas educacionais) não altera em substância a argumentação aqui apresentada.

3. Esse termo, aplicado por mim e por outros psicólogos, em discussões acerca do papel social do psicólogo, em meados da década de 1990, visava justamente à crítica do recurso desenfreado de isolamento do indivíduo sob o argumento de tentar ajudá-lo a "superar suas próprias dificuldades", "ser adaptado às situações adversas", e por aí afora; recurso mais ou menos independente das bases teóricas que os profissionais juravam compartilhar. Distinguíamos, por certo, o que chamávamos de clinicalismo da perspectiva clínica (individual ou grupal) de tratamento psicológico, consagrada desde a origem da psicologia moderna.

4. Parcela significativa das informações a que recorri para discutir questões centrais da psicopedagogia pode ser encontrada em várias passagens dos cinco volumes organizados, no início dos anos de 1970, por Maurice Debesse e Gaston Mialaret, sob o título geral: Tratado das ciências pedagógicas (1974), e especificadas nas referências.

\section{Referências bibliográficas}

BEAUFILS, F. O s centros psicopedagógicos, os centros de reeducação e de psicoterapia. In: D ebesSe, M.; Mialaret, G. (O rg). Tratado das ciências pedagógicas. São Paulo: Nacional; EdusP, 1974. v.5, p. 325-334. 
BLEY, R. A pedagogia curativa escolar. In: Debesse, M.; Mialaret, G. (O rg). Tratado das ciências pedagógicas. São Paulo: Nacional; ED USP, 1974. v.5, p. 335-365.

CONSELHO REG IONAL DE PSICOLOGIA - 6ํㅡㄹ Região. Manual do CR P-06. São Paulo, 1995.

DEBESSE, M.; MIALARET, G. (O rg). Tratado das ciências pedagógicas. São Paulo: Nacional; EdUSP, 1974. 5 v.

LEBOUTET, L. Psicopedagogia das ciências da natureza. In: D EBESSE, M.; Mialaret, G. (O rg). Tratado das ciências pedagógicas. São Paulo: Nacional; EDUSP, 1974. v.5, p. 243-255.

LEFĖVRE, L. Psicopedagogia das classes novas. In: DebesSe, M.; Mialaret, G. (O rg). Tratado das ciências pedagógicas. São Paulo: Nacional; EDUSP, 1974. v.5, p. 85-128.

VIAL, J. O pedocentrismo. In: Debesse, M.; Mialaret, G. (Org). Tratado das ciências pedagógicas. São Paulo: Nacional; EDUSP, 1974. v.2, p. $453-485$. 